ARTICLE

https://doi.org/10.1038/s41467-019-09618-8

\title{
Radical-mediated C-S bond cleavage in C2 sulfonate degradation by anaerobic bacteria
}

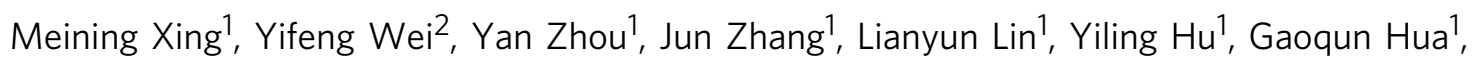

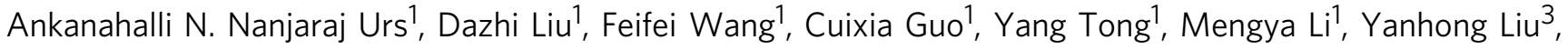
Ee Lui Ang ${ }^{2}$, Huimin Zhao (D) ${ }^{2,4}$, Zhiguang Yuchi id ${ }^{1} \&$ Yan Zhang (iD ${ }^{1}$

Bacterial degradation of organosulfonates plays an important role in sulfur recycling, and has been extensively studied. However, this process in anaerobic bacteria especially gut bacteria is little known despite of its potential significant impact on human health with the production of toxic $\mathrm{H}_{2} \mathrm{~S}$. Here, we describe the structural and biochemical characterization of an oxygensensitive enzyme that catalyzes the radical-mediated C-S bond cleavage of isethionate to form sulfite and acetaldehyde. We demonstrate its involvement in pathways that enables C2 sulfonates to be used as terminal electron acceptors for anaerobic respiration in sulfateand sulfite-reducing bacteria. Furthermore, it plays a key role in converting bile salt-derived taurine into $\mathrm{H}_{2} \mathrm{~S}$ in the disease-associated gut bacterium Bilophila wadsworthia. The enzymes and transporters in these anaerobic pathways expand our understanding of microbial sulfur metabolism, and help deciphering the complex web of microbial pathways involved in the transformation of sulfur compounds in the gut.

\footnotetext{
${ }^{1}$ Tianjin Key Laboratory for Modern Drug Delivery \& High-Efficiency, Collaborative Innovation Center of Chemical Science and Engineering, School of Pharmaceutical Science and Technology, Tianjin University, 300072 Tianjin, China. ${ }^{2}$ Metabolic Engineering Research Laboratory, Institute of Chemical and Engineering Sciences, Agency for Science, Technology and Research (A*STAR), Singapore 138669, Singapore. ${ }^{3}$ Technical Institute of Physics and Chemistry, Chinese Academy of Sciences, Beijing 100190, China. ${ }^{4}$ Department of Chemical and Biomolecular Engineering, University of Illinois at Urbana-Champaign, 600 South Mathews Avenue, Urbana, IL 61801, USA. These authors contributed equally: Meining Xing, Yifeng Wei Correspondence and requests for materials should be addressed to H.Z. (email: zhao5@illinois.edu) or to Z.Y. (email: yuchi@tju.edu.cn) or to Y.Z. (email: yan.zhang@tju.edu.cn)
} 
T he C2 sulfonates aminoethylsulfonate (taurine) and hydroxyethylsulfonate (isethionate) are widespread in the environment, originating from both biotic and industrial sources. Despite the chemical inertness of the sulfonate C-S bond, microbes have evolved a variety of enzymes and pathways to incorporate the carbon and sulfur into their metabolism, and play an important role in the degradation of these $\mathrm{C} 2$ sulfonates ${ }^{1,2}$. Isethionate, as a fatty acyl ester, is a component of common industrial surfactants, and is present in some habitats as an industrial pollutant ${ }^{2}$, where bacterial metabolism accelerates mineralization of the sulfonate sulfur, returning it to the sulfur cycle.

Taurine and isethionate are also present in the human body, and have great relevance to human health. Taurine is a key osmolyte in mammals, and one of the most abundant amino acids in the human body ${ }^{3}$. Excretion of taurine takes place through the gut in the form of taurine-conjugated bile salts ${ }^{4}$, stimulated by a diet high in meat and fat. Hydrolysis by bacterial bile salt hydrolases releases taurine as a major constituent of the sulfur pool available to gut bacteria. Isethionate in the human body is thought to be a product of taurine metabolism by gut bacteria ${ }^{5}$. While carbon and nitrogen are largely fermented to innocuous end-products, the sulfonate sulfur are converted by the consortium of anaerobic gut bacteria into toxic $\mathrm{H}_{2} \mathrm{~S}^{4}$ implicated in inflammation, colorectal cancer and gastrointestinal dysbiosis ${ }^{4,6}$.

The rich enzymology of bacterial taurine and isethionate degradation has been studied over the past five decades ${ }^{7}$, revealing diverse strategies for C-S bond cleavage (Supplementary Fig. 1). $\mathrm{O}_{2}$-dependent enzymes such as $\mathrm{TauD}$ and $\mathrm{SsuD}^{8,9}$ catalyze $\mathrm{C}-\mathrm{S}$ cleavage of taurine and isethionate respectively, through activated oxygen species generated under aerobic conditions (Supplementary Fig. 1a). Sulfoacetaldehyde acetyltransferase $(\mathrm{Xsc})^{10}$ catalyzes $\mathrm{C}-\mathrm{S}$ cleavage of sulfoacetaldehyde, a common intermediate in both taurine and isethionate degradation, to form sulfite and acetyl-phosphate (Supplementary Fig. 1b, c). The catalytic mechanism of Xsc requires a thiamine pyrophosphate cofactor, and occurs under both aerobic and anaerobic conditions.

Despite its importance, the microbial transformation of C2 sulfonate sulfur in anoxic environments, which includes a significant fraction of the biosphere and the human gut, remains poorly understood. Sulfonates are particularly important substrates for sulfate- and sulfite-reducing bacteria (SSRB $)^{1,2}$, which are strict anaerobes that use sulfite as a terminal electron acceptor (TEA) for anaerobic respiration, reducing it to $\mathrm{H}_{2} \mathrm{~S}$. In certain environments, such as the gut environment and marine microbial mats ${ }^{11}$, sulfonates constitute a major source of oxidized sulfur compounds for SSRB metabolism.

Two decades ago, it was found that certain SSRB could use taurine and isethionate as TEAs, reducing the sulfonate sulfur to $\mathrm{H}_{2} \mathrm{~S}^{1,2}$. Preliminary experiments suggested that the pathway requires sulfonate $\mathrm{C}-\mathrm{S}$ cleavage, liberating sulfite for subsequent reduction by the dissimilatory sulfite reductase ${ }^{12}$. However, the complete pathways for anaerobic taurine and isethionate metabolism in SSRB have not yet been determined. In particular, many SSRB do not possess Xsc, necessitating new enzymes that catalyze C-S cleavage without relying on $\mathrm{O}_{2}$.

In this work, we report the identification of an $\mathrm{O}_{2}$-sensitive isethionate sulfo-lyase, which catalyzes $\mathrm{C}-\mathrm{S}$ cleavage of isethionate via a radical-dependent mechanism. We further demonstrate its involvement in pathways for the degradation of isethionate and taurine by prominent SSRB from the human gut.

\section{Results}

Identification of GUF as a candidate sulfonate $\mathrm{C}-\mathrm{S}$ lyase. We discovered an anaerobic $\mathrm{C} 2$ sulfonate $\mathrm{C}-\mathrm{S}$ lyase candidate while carrying out a bioinformatics study on the glycyl radical enzyme (GRE) superfamily. GREs catalyze challenging chemical transformations using the high reactivity of the protein-based radical to initiate catalytic reactions ${ }^{13}$, and recent studies have yielded several new GREs with novel catalytic chemistry ${ }^{13-15}$. The essential $\mathrm{O}_{2}$-sensitive glycyl radical (G•) cofactor is generated by an activating enzyme through chemistry involving $\mathrm{S}$ adenosylmethionine (SAM) and a $[4 \mathrm{Fe}-4 \mathrm{~S}]^{1+}$ cluster $^{16}$.

To facilitate large-scale analysis of GRE sequences, a sequence similarity network (SSN) ${ }^{17}$ for 14228 unique sequences in the InterPro family IPR004184 (release 68.0) was constructed using the web-based Enzyme Function Initiative Enzyme Similarity Tool (EFI-EST) ${ }^{18}$, and displayed using Cytoscape v3. $5^{19}$ at an Evalue threshold of $10^{-299}$ ( $>\sim 60 \%$ sequence identity is required to draw an edge), which separates previously characterized GREs with mechanistically distinct catalytic activities into distinct clusters (Supplementary Fig. 2). While examining the remaining uncharacterized GRE clusters, we noticed a particular cluster containing a GRE of unknown function (GUF), dominated by sequences from phylogenetically diverse SSRB (Supplementary Fig. 2, Supplementary Data 1). Because most GREs are involved in fermentative rather than respiratory metabolism, the association of GUF with SSRB suggested a link to their unique mode of anaerobic respiration using sulfite as terminal electron acceptors (TEAs).

In some SSRB, GUF is associated with microcompartment proteins $^{20}$ (Fig. 1a), providing a clue regarding its potential substrate. Microcompartment-associated enzymes are often 1,2eliminases acting on substrates containing a $\mathrm{C} 1-\mathrm{OH}$ group and a C2 leaving group, generating acetaldehyde or propionaldehyde as products. These include the adenosylcobalamin-dependent enzymes diol dehydratase and ethanolamine-ammonia lyase $(\mathrm{EAL})^{21}$, and the GREs choline-trimethylamine lyase $(\mathrm{CutC})^{22}$, and propanediol dehydratase $(\mathrm{PDH})^{13}$. GUF is also associated with a three-subunit TRAP transporter (Fig. 1a), a family of transporters that catalyze the import of organic acids and aliphatic sulfonates ${ }^{23,24}$. Taken together, we hypothesized that GUF acts on isethionate, catalyzing C-S cleavage to generate acetaldehyde and sulfite (Fig. 1b).

GUF is an isethionate sulfo-lyase. To test this hypothesis, we recombinantly produced GUF (UniProt: Q727N1) and its adjacent activating enzyme (Q727N0) from the model SSRB Desulfovibrio vulgaris Hildenborough (Supplementary Fig. 3). Biochemical characterization confirmed that GUF was indeed an isethionate sulfo-lyase (Fig. 2, vide infra), and we renamed GUF and its activating enzyme IseG and IseH, respectively. Like most of the other GREs, the purified recombinant IseG exists as a dimer in solution, as analysed by size exclusion chromatography (SEC) (Supplementary Fig. 4).

Sequence alignments of IseH with other previously characterized GRE activating enzymes and ferredoxins from different origins show that, like many other activating enzymes, IseH contains the essential CX2CX3C motif that coordinates the radical SAM [4Fe-4S] cluster, as well as a widely conserved 8-cysteine motif in ferredoxin coordinating two [4Fe-4S] clusters (Supplementary Fig. 5a). ${ }^{25}$ Biochemical experiments and sequence analysis of hydroxyphenylacetate decarboxylase activating enzyme by Selvaraj et al. ${ }^{25}$ support this. Anaerobic reconstitution of the IseH [ $4 \mathrm{Fe}-4 \mathrm{~S}$ ] clusters resulted in $5.9 \pm 0.1 \mathrm{Fe}$ and $8.4 \pm 0.1 \mathrm{~S}$ per monomer (out of the theoretical maximum of $12 \mathrm{Fe}$ and $12 \mathrm{~S}$ ) (Supplementary Fig. 5b), suggesting that our protocol gives rise to incomplete reconstitution and possibly a fraction of [3Fe-4S] clusters. ${ }^{26}$ IseH exhibited a typical UV-Vis spectrum for a [4Fe-4S] cluster-containing protein (Supplementary Fig. 6). Like 

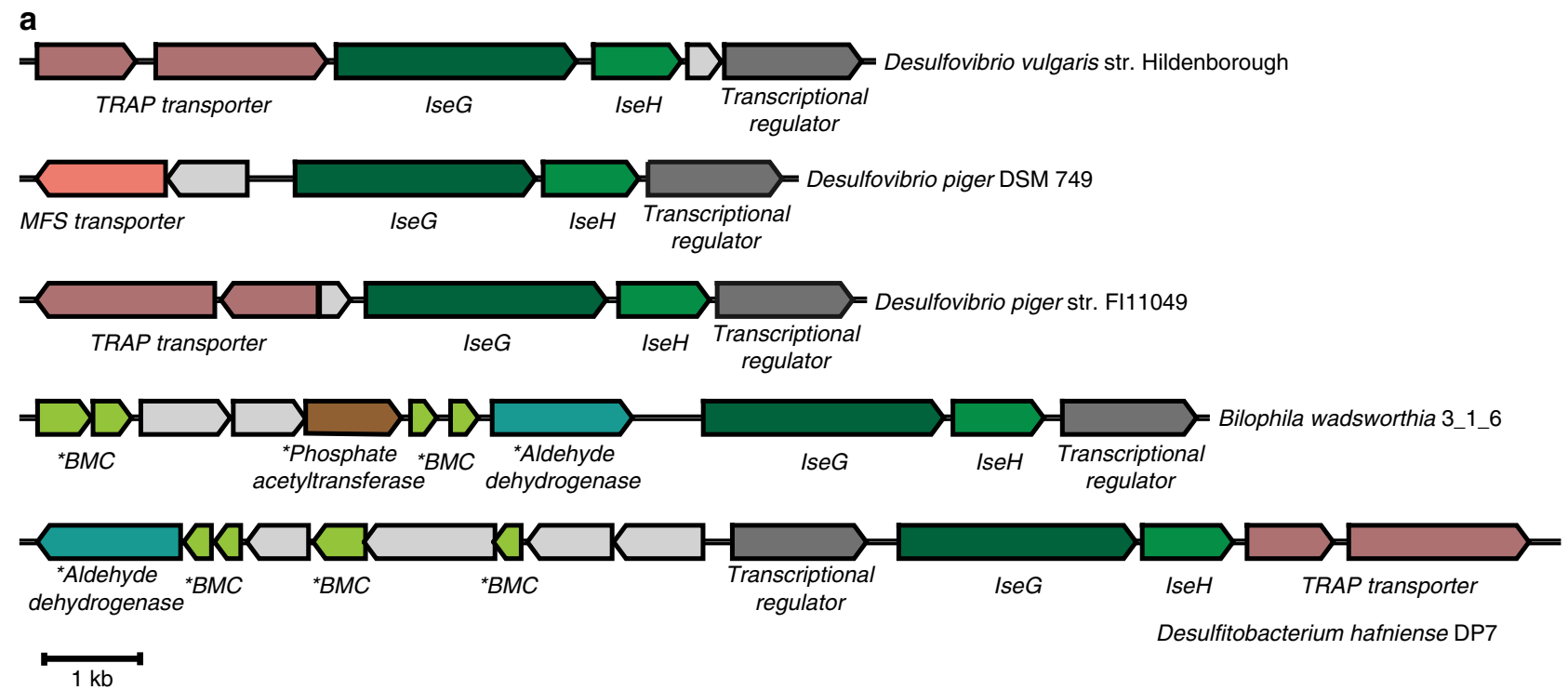

*Microcompartment-associated proteins

b

$\mathrm{HO} \sim \mathrm{SO}_{3}^{-} \frac{\mathrm{IseG}}{-\mathrm{H}^{+}} \longrightarrow \mathrm{O}+\mathrm{SO}_{3}^{2-}$

Fig. 1 Genome neighborhood and proposed reaction. a The IseG genome neighborhoods in sulfate-reducing bacteria Desulfovibrio vulgaris str. Hildenborough, Desulfovibrio piger DSM749, Desulfovibrio piger str. F111049 (a gram-negative sulfate-reducing bacterium), Desulfitobacterium hafniense DP7 (a gram-positive sulfite-reducing bacterium) and sulfite-reducing bacterium Bilophila wadsworthia 3_1_6 (a gram-negative sulfite-reducing bacterium) are shown. In many cases, IseG is associated with a TRAP transporter and microcompartment proteins. b Proposed IseG-catalyzed reaction

other radical SAM enzymes, IseH cleaved SAM to form 5'deoxyadenosine in the presence of a strong reductant $\mathrm{Ti}$ (III) citrate (Supplementary Fig. 7). Electron paramagnetic resonance (EPR) spectroscopy showed that IseH could install the G• on IseG, forming 0.4 (out of a theoretical maximum of 1$)^{16}$ radicals per dimer (Fig. 2a).

Incubation of activated IseG with isethionate resulted in its conversion to acetaldehyde (Fig. 2b) and sulfite (Supplementary Fig. 8). Under conditions for full substrate conversion, the stoichiometry of isethionate added to acetaldehyde and sulfite produced was 1:1:1 (Fig. 2c). No activity was detected with taurine or ethanolamine as substrates, indicating high substrate specificity (Fig. 2c). The kinetic parameters of IseG support the physiological relevance of this reaction $\left(k_{\mathrm{cat}}=91.6 \pm 3.3 \mathrm{~s}^{-1}\right.$, $K_{\mathrm{m}}=44.8 \pm 3.5 \mathrm{mM}$ ) (Supplementary Figs. 9, 10).

Crystal structure of isethionate-bound IseG. To further investigate the mechanism of $\mathrm{C}-\mathrm{S}$ cleavage by IseG, we determined the crystal structure of isethionate-bound IseG at $2.4 \AA$ (Fig. 3, Supplementary Fig. 11). The P21 crystals contain four monomers per asymmetric unit, each exhibiting a canonical $\beta / \alpha$ barrel fold common to other GREs (Supplementary Fig. 11a). The superimposed structures of IseG and its closest structurally characterized relative $\mathrm{CutC}^{22}$ display a root mean square deviation (RMSD) of $1.25 \AA$ between $503 \mathrm{Ca}$ atoms. The positions of the isethionate $\mathrm{C} 1$ and $\mathrm{OH}$ groups relative to the glycyl and thiyl radical residues required for substrate activation, and a conserved glutamate required for deprotonation of the isethionate $\mathrm{OH}$ group (Fig. 3a-c) are consistent with our working hypothesis for the catalytic mechanism for C-S cleavage (Fig. 3d), which we propose based on analogies to the mechanism of other GRE $\mathrm{C}-\mathrm{O}$ and $\mathrm{C}-\mathrm{N}$ lyases ${ }^{22,27}$.

The orientation of the isethionate $\mathrm{C} 2$ and sulfonate-leaving group differs greatly from choline in CutC. A $98.5^{\circ}$ rotation of the $\mathrm{C} 1-\mathrm{C} 2$ axis in isethionate vs. choline (Supplementary Fig. 11b) results in the pro- $R$ hydrogen of isethionate being oriented for abstraction by the thiyl radical (Fig. 3c). The hydrogen of the opposite stereochemistry is thought to be abstracted in all other mechanistically related GREs: CutC, propanediol dehydratase, glycerol dehydratase, and ribonucleotide reductase ${ }^{28}$. Despite overall structural similarities between IseG and CutC, two substrate-interacting loops (loop A and B) in IseG are shifted by up to $6.8 \AA$ A relative to CutC (Fig. 3b, Supplementary Fig. 11c), resulting in dramatic changes to the binding pocket structure and substrate-coordinating residues.

The sulfonate group of isethionate is coordinated by Arg187, Gln191, and Arg676 of IseG and one water molecule through an extensive hydrogen bond network (Fig. 3a). The conformation of isethionate is further stabilized by van der waals contact with Phe680, Ile190, and Thr310. The three sulfonate-coordinating residues (Arg187, Gln191, and Arg676) are conserved in the sequences within the "IseG" cluster of the GRE SSN (Supplementary Data 1), but are absent in CutC and other GREs (Supplementary Fig. 12), supporting the proposal that the "IseG" cluster enzymes are involved in sulfonate degradation.

Isethionate dissimilation in D. piger. Examination of the "IseG" cluster shows that IseG is present in diverse environmental and human-associated SSRB (Supplementary Data 1), and we next investigated the involvement of IseG in sulfonate degradation in these bacteria. Certain SSRB, including Desulfovibrio spp., Desulfitobacterium spp., and Bilophila wadsworthia have been reported to use isethionate as a TEA, generating acetate and $\mathrm{H}_{2} \mathrm{~S}^{29,30}$. Among the sequenced strains, this ability correlates with the presence of IseG (Supplementary Table 1). A previously discovered pathway for isethionate degradation in non-SSRB environmental bacteria involves a membrane-bound flavindependent isethionate dehydrogenase (IseJ) and $\mathrm{Xsc}^{31}$ (Supplementary Fig. 1b). However, a BLAST search for IseJ revealed no homologs in SSRB, and not all isethionate-dissimilating SSRB 
a

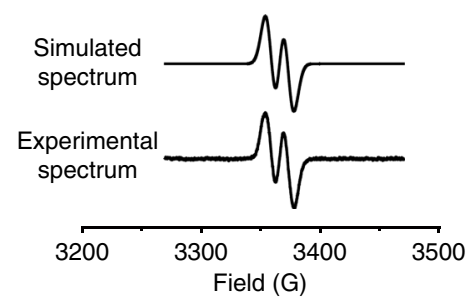

b
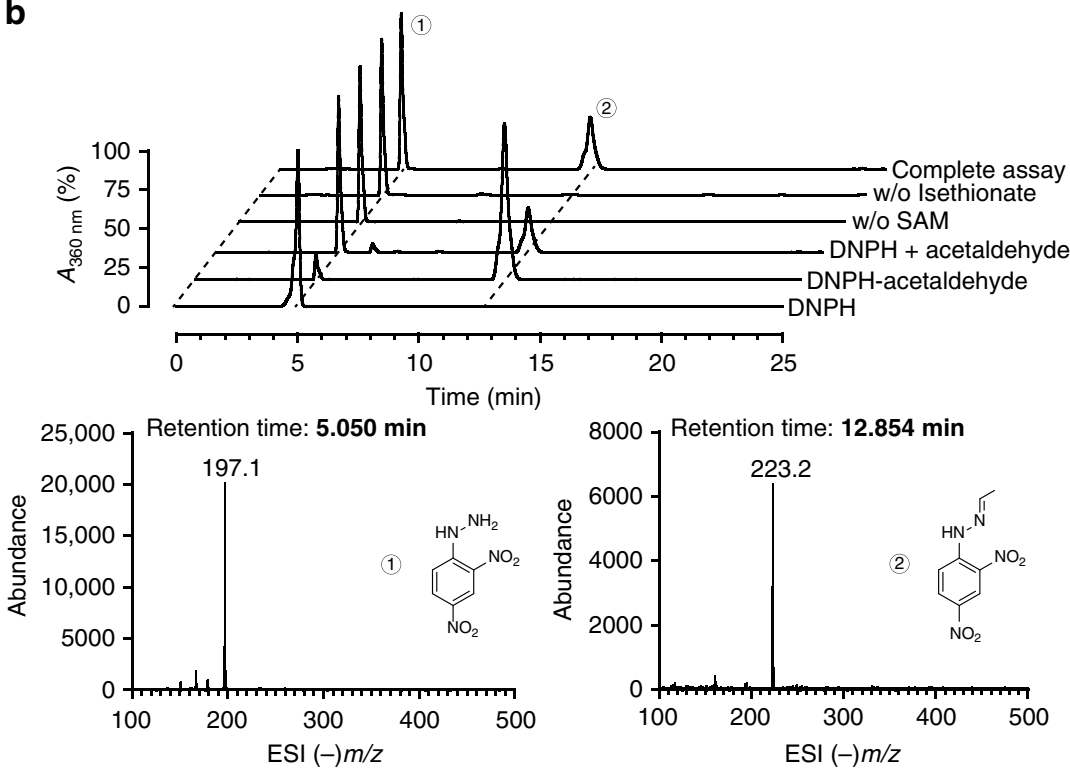

C

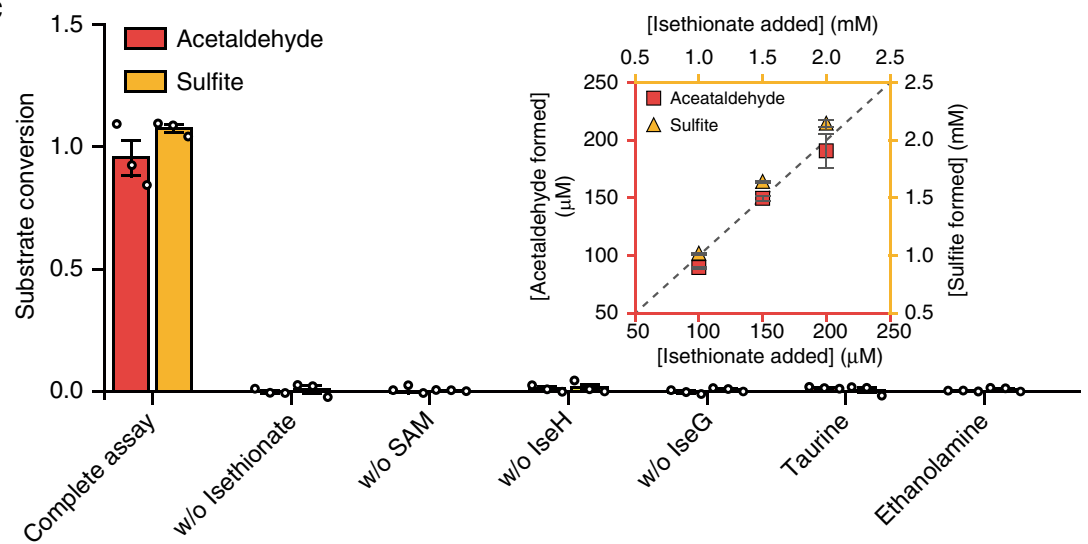

Fig. 2 EPR spectra and enzymatic assays. a X-band EPR spectrum of IseG reconstituted with IseH and SAM in the presence of reductant (Ti (III) citrate). b Detection of acetaldehyde formation in the IseG-catalyzed isethionate cleavage using LC-MS/MS. HPLC elution profiles of the DNPH derivatives from the reaction products, reaction negative controls, and authentic standards (theoretical mass of the monoanion of DNPH $=197.1$, and DNPH-acetaldehyde =223.2), are presented. Negative ionization mass spectra of the peaks 1 and 2 from the HPLC trace show that they contain DNPH and DNPH-

acetaldehyde, respectively. c Enzymatic assays showing the fraction of substrate converted to acetaldehyde and sulfite under different reaction conditions, demonstrating the reaction requirements and substrate specificity. The inset shows the stoichiometric conversion of isethionate into acetaldehyde and sulfite. The error bars represent the standard deviation of three individual experiments. Source data are provided as a Source Data file

contain Xsc (Supplementary Table 1), suggesting a distinct pathway for isethionate degradation in SSRB.

We further studied the most prevalent human gut sulfatereducing bacterium Desulfovibrio piger DSM 74932, which contains IseG (Fig. 1a) but not Xsc (Supplementary Table 1). When lactate is supplied as the carbon and electron source, growth was supported with sulfate or isethionate, but not taurine, as the sole TEA. Growth was accompanied by the formation of a characteristic black FeS precipitate in the medium. This observation, together with the methylene blue assay for the headspace gas in the anaerobic culture vials, indicate $\mathrm{H}_{2} \mathrm{~S}$ formation as previously reported for other Desulfovibrio species $^{2,30}$ (Supplementary Fig. 13). SDS-PAGE analysis revealed a prominent protein band with molecular weight of $\sim 95 \mathrm{kD}$ (Fig. 4a), present in isethionate- but not sulfate-grown cells, as observed but not identified with several other SSRB by Leadbetter et. al. nearly 20 years ago ${ }^{29}$. Mass spectrometric analysis now identified this protein as IseG (B6WXM2, Supplementary Data 2).

We next investigated the mechanism for isethionate import. In $D$. piger DSM 749, IseG is associated with a major facilitator 
a

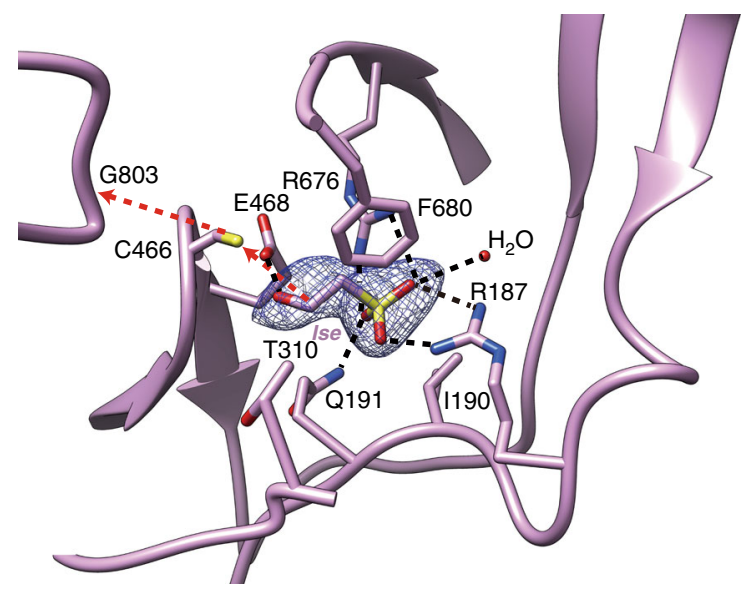

b

C

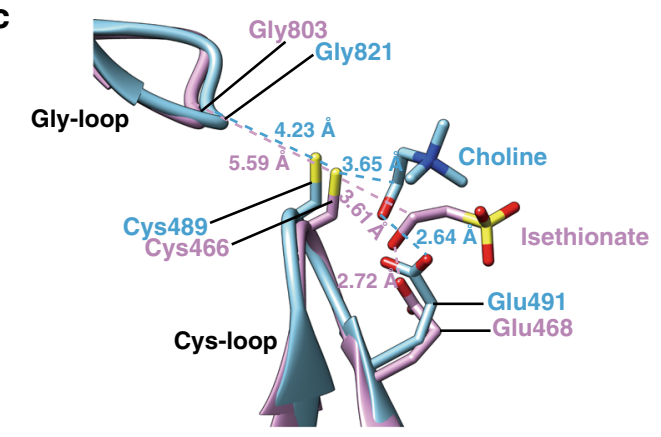

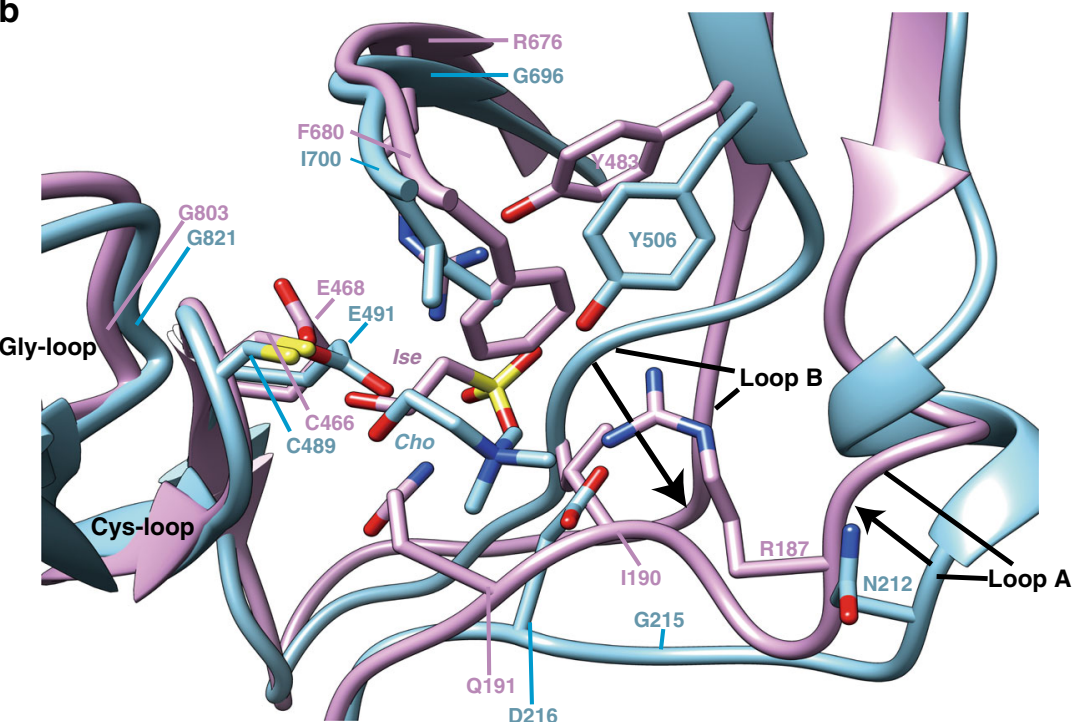

Cys-loop

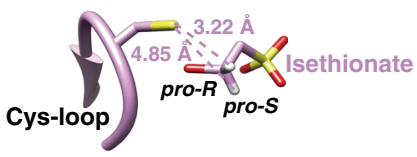

d<smiles>CCCC(C)OS(=O)(=O)CCO</smiles>

Cys466

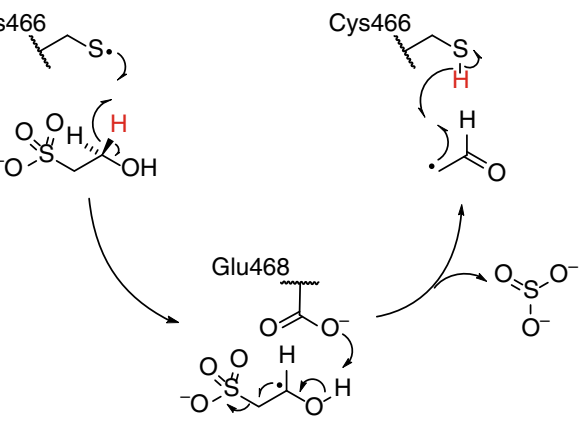

Fig. 3 IseG active site structure. a IseG active site in complex with the substrate isethionate. The proposed pathway for hydrogen atom transfer is indicated by red arrows, and all hydrogen bonds are indicated by black dashed lines. 2Fo-Fc electron densities for isethionate are shown at 1.0 $\mathbf{\sigma}$. b Superposition of the IseG active site (plum) with CutC active site (cyan, PDB code 5FAU). Key residues involved in substrate binding and radical chemistry are displayed and labeled. The conformational changes in two substrate-coordinating loops are indicated by black arrows. c Structural model of the Gly-loop, Cys-loop, and the substrates. The distances between the key atoms are indicated. Comparison of the orientation of the modeled C1 hydrogens of isethionate (plum) and choline (cyan), suggesting that different enantiotopic hydrogens are abstracted by the thiyl radical. The distances between thiyl radical site and $\mathrm{C} 1 \mathrm{hydrogens}$ are labeled. d Proposed mechanism of isethionate cleavage by GUF (IseG). The thiyl radical, which is transiently generated by the G• cofactor in all GREs, abstracts a hydrogen (shown in red) from the substrate isethionate, and returns it to form the product acetaldehyde 
a
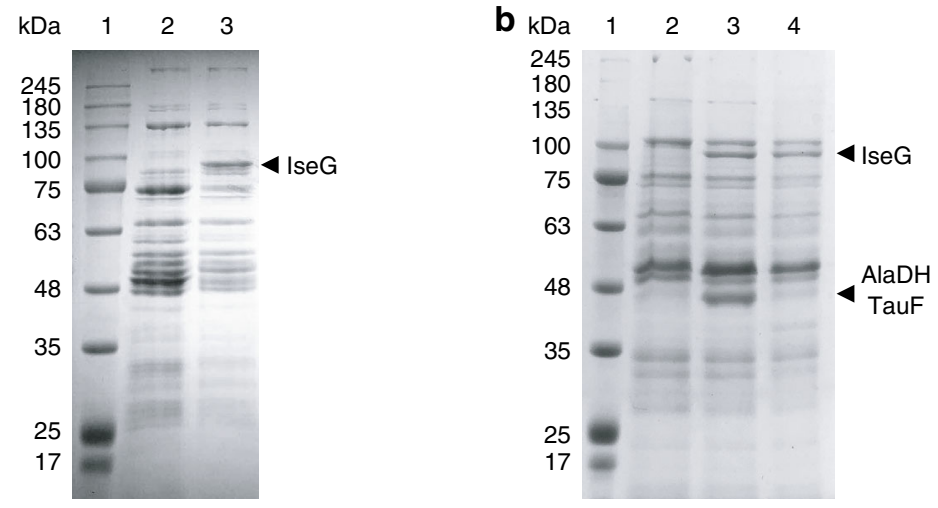

C

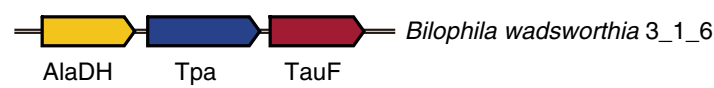

d

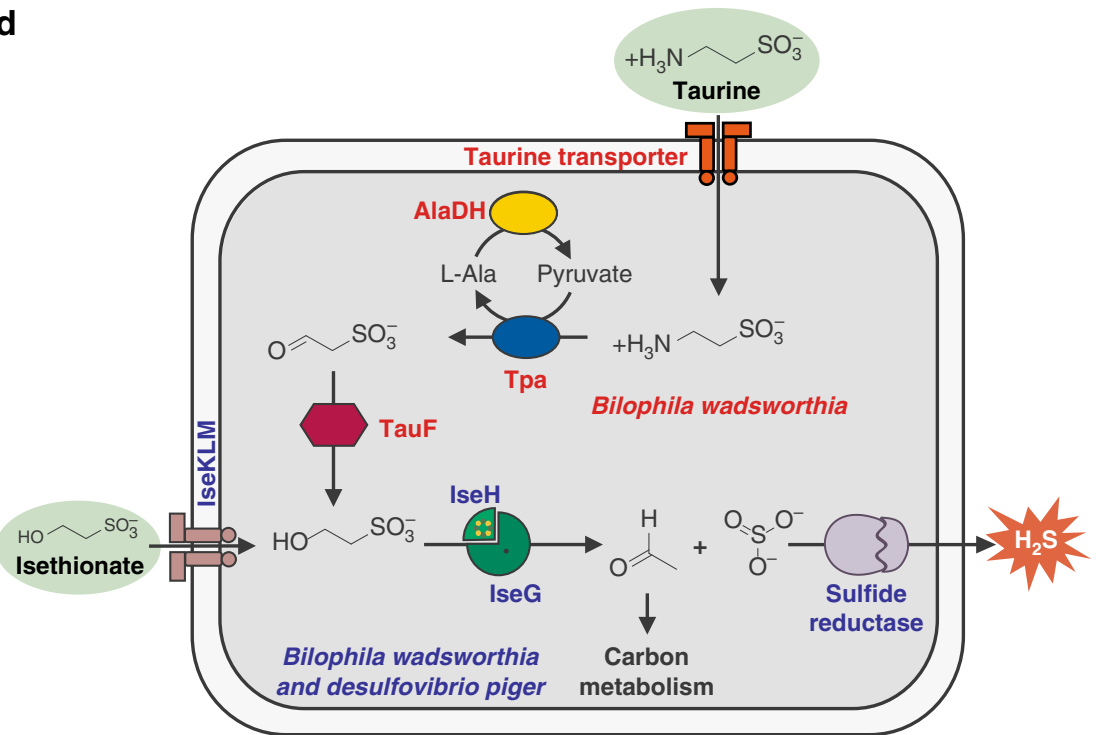

Fig. 4 C2 sulfonate induced IseG-dependent pathway in SSRB. a SDS-PAGE analysis of D. piger grown on lactate plus sulfate (lane 2) or isethionate (lane 3). The arrow indicates a $\sim 95-\mathrm{kD}$ band identified as IseG. b B. wadsworthia grown on pyruvate plus thiosulfate (lane 2), taurine (lane 3) or isethionate (lane 4). The arrows indicate a $\sim 95-\mathrm{kD}$ band identified as IseG, and a $\sim 40-\mathrm{kD}$ band containing both AlaDH and TauF. c Genome neighborhood of B. wadsworthia Tpa and AlaDH, showing the proximity to a gene in the ADH superfamily, found to be a NADH-dependent sulfoacetaldehyde reductase TauF. d Proposed pathways for dissimilation of isethionate and taurine in D. piger and B. wadsworthia. Source data are provided as Supplementary Data 2-5

superfamily (MFS) transporter (Fig. 1a), a family of transporters that transport diverse substrates, which includes the putative isethionate MFS transporter IseU (Supplementary Fig. $1 \mathrm{~b})^{31}$. In other SSRB, including the D. piger strain FI11049, the IseG is associated with a TRAP transporter (Fig. 1a) ${ }^{23}$. The TRAP transporter family includes the putative isethionate TRAP transporter IseKLM, which is associated with other isethionate degradation pathways (Supplementary Fig. $1 b)^{31}$. We chose to focus on the TRAP transporter as it is dependent on a soluble periplasmic substrate-binding subunit, which is amenable to biochemical characterization by isothermal titration calorimetry (ITC). The recombinant substrate-binding subunit (A0A1K1LFE7) of the IseG-associated TRAP transporter in D. piger strain FI11049 showed enthalpydriven binding of isethionate with a physiologically relevant $K_{\mathrm{d}}$ of $0.5 \mu \mathrm{M}$ (Supplementary Fig. 14a), but no binding of taurine (Supplementary Fig. 14b), confirming that it is an isethionate transporter. This pathway for uptake and dissimilation of isethionate (Fig. 4d) demonstrates a role for IseG in generating electron acceptors for anaerobic respiration.
Isethionate and taurine dissimilation in B. wadsworthia. The disease-associated human gut sulfite-reducing bacterium Bilophila wadsworthia is one of a small number of SSRB reported to utilize taurine as the sole carbon and energy source for growth, generating acetate, ammonia and $\mathrm{H}_{2} \mathrm{~S}^{30}$. It contains IseG (Fig. 1a), and we next investigated the involvement of IseG in taurine degradation in Bilophila. In the non-SSRB Ruegeria pomeroyi DSS-3, which has served as a paradigm for taurine dissimilation, taurine pyruvate aminotransferase (Tpa) converts taurine to sulfoacetaldehyde, followed by C-S cleavage by Xsc (Supplementary Fig. 1c) $)^{7,33}$. Pyruvate, required by Tpa, is regenerated by alanine dehydrogenase $(\mathrm{AlaDH})$. In $B$. wadsworthia RZATAU, Tpa and AlaDH activities have been detected in lysates of taurine-grown cells, and their primary sequences have been identified ${ }^{34,35}$. However, Xsc activity could not be detected in the lysates ${ }^{1}$, and a BLAST search for Xsc revealed no homologs in both of the sequenced Bilophila species, suggesting a distinct pathway for taurine degradation in Bilophila.

In the genome of $B$. wadsworthia 3_1_6, Tpa occurs immediately downstream of AlaDH (Fig. 4c). Closer inspection 
revealed an uncharacterized metal-dependent alcohol dehydrogenase (Fe-ADH) (E5Y946) immediately downstream of Tpa. The recombinant protein, which we renamed TauF, catalyzed NADH-dependent reduction of sulfoacetaldehyde (Supplementary Fig. 15), generating isethionate that could subsequently be cleaved by IseG. This suggested a possible IseG-dependent taurine degradation pathway in Bilophila (Fig. 4d).

Growth of B. wadsworthia RZATAU was supported with pyruvate plus thiosulfate, or with either taurine or isethionate as the sole substrates, as previously reported ${ }^{30}$. Growth was accompanied by the formation of a characteristic black FeS precipitate in the medium, indicating $\mathrm{H}_{2} \mathrm{~S}$ formation, as previously reported ${ }^{30}$. SDS-PAGE analysis revealed that prominent protein bands with molecular weight of $\sim 95 \mathrm{kD}$ (Fig. $4 \mathrm{~b}$ ), were present in isethionate- and taurine-grown cells but not thiosulfate-grown cells. Mass spectrometric analysis identified the proteins as IseG (E5Y378, Supplementary Data 3 and Supplementary Data 4). Taurine-grown cells also exhibited a prominent protein band with molecular weight of $\sim 40 \mathrm{kD}$ (Fig. 4b), identified as AlaDH and TauF (top two hits in Supplementary Data 5). This demonstrates that IseG-dependent pathways are responsible for the dissimilation of both isethionate and taurine in Bilophila (Fig. 4d), thus playing a critical role in the unique metabolic niche of this pathobiont, which relies on these sulfonates as TEAs in the gut environment ${ }^{6}$.

\section{Discussion}

Discovery of the C-S lyase IseG adds to the chemical diversity of radical-dependent 1,2-lyases, which have hitherto included only $\mathrm{C}-\mathrm{O}$ lyases (GRE and B12-dependent diol dehydratases) and $\mathrm{C}-\mathrm{N}$ lyases (GRE CutC and B12-dependent EAL) ${ }^{21,28}$. The catalytic mechanisms of GRE and B12-dependent diol dehydratases have been studied in detail, both experimentally ${ }^{36}$ and computationally ${ }^{27}$, and are thought to proceed via different reaction mechanisms. In the proposed mechanisms, the reaction proceeds via a direct loss of the leaving group for GREs, and via a 1,2-shift of the leaving group for B12-dependent lyases ${ }^{27,36}$. Further biochemical and computational studies are clearly needed to investigate the $\mathrm{C}-\mathrm{S}$ lyase reaction, to ascertain whether it may occur via one or both types of catalytic mechanism.

Our in vivo experiments with the two prominent human gut SSRB $D$. piger and $B$. wadsworthia demonstrate the involvement of the $\mathrm{O}_{2}$-sensitive IseG in $\mathrm{C} 2$ sulfonate dissimilation pathways in SSRB, and resolve the decades-old mystery of the mechanism of C-S cleavage in these strict anaerobes. Just as Xsc serves a hub in diverse pathways for $\mathrm{C} 2$ sulfonate degradation in many environmental bacteria, the $\mathrm{O}_{2}$-sensitive IseG may serve as a hub for alternative pathways for $\mathrm{C} 2$ sulfonate degradation in strict anaerobes, thereby serving as a genetic marker for the exploration of sulfonate-related biochemical pathways in the anaerobic microbiome.

IseG-dependent dissimilative pathways may play important roles in gut SSRB, highlighted by the presence of IseGH in all five SSRB genomes currently in the NIH Human Microbiome Project, including Desulfitobacterium hafniense DP7 (G9XK69), D. piger ATCC 29098 (B6WXM2), Desulfovibrio sp. 6_1_46AFAA (G1UPG5), B. wadsworthia 3_1_6 (E5Y378), and Bilophila sp. 4_1_30 (G1V3L3). In addition, the IseG-dependent pathway is the only known pathways for sulfonate degradation in D. piger and B. wadsworthia. The abundance of SSRB correlates with many human diseases ${ }^{37,38}$, and have been shown to alter the levels of $\mathrm{H}_{2} \mathrm{~S}^{39}$, a signaling molecule in plasma and many tissues $^{40}$, with significant effects on neuronal activity and behavior $^{41}$. Therefore, pathways involving IseGH, will impact future microbiome studies and present therapeutic targets for the treatment of human diseases.

\section{Methods}

Materials and general methods. Lysogeny Broth (LB) medium was prepared with yeast extract and tryptone purchased from Oxoid, England. Anaerobe Basal Broth (ABB) rich medium was purchased from Rishui Biotech., Qingdao, China. Methanol and acetonitrile used for liquid chromatography-mass spectrometry (LC MS) were high-purity solvents from Concord Technology. Formic acid was purchased from Merck. Water used in this work was ultrapure deionized water from Millipore Direct-Q. Oligonucleotide primers were synthesized by General Biosystems, Inc (Supplementary Table 2). Talon Cobalt resins were purchased from Clonetech. All other reagents unless specified were purchased from Sigma/Aldrich

All protein purification chromatographic experiments were performed on an “ÄKTA pure" or "ÄKTA prime plus" FPLC machine equipped with appropriate columns (GE Healthcare). Protein concentrations were calculated from the absorption at $280 \mathrm{~nm}$ measured using an Eppendorf BioPhotometer D30 or determined by Bradford assays referring to the standard curves established with a series of concentrations of bovine serum albumin (BSA). Anaerobic experiments were conducted in a Lab2000 glovebox (Etelux) under an atmosphere consisting of $\mathrm{N}_{2}$ with less than 5 ppm $\mathrm{O}_{2}$.

Plasmid construction. DNA fragments containing codon-optimized ORFs of IseG, IseH, $D p$ IseK and $B w$ TauF were synthesized and inserted into plasmids by General Biosystems, Inc (Supplementary Data 6). Plasmids used in this study were pET-28a $(+)$ and modified pET28 vectors including HMT vector (containing, in tandem, a His $_{6}$-tag, maltose binding protein (MBP) and a Tobacco Etch Virus (TEV) protease cleavage site, followed by the construct of interest), and HT vector (containing a $\mathrm{His}_{6}$-tag and a TEV protease cleavage site, followed by the construct of interest) ${ }^{42}$. For the production of IseG for biochemical studies, the Ise $G$ fragment was inserted into pET-28a $(+)$ at the $\mathrm{NdeI} / \mathrm{XhoI}$ sites to form pET-28a(+)-His ${ }_{6}$-IseG. For the production of soluble IseH, the $I s e H$ fragment was inserted into the HMT vector at the $S s p I$ site. For the production of high purity IseG with an N-terminal 23-a.a truncation for crystallography, the Ise G fragment was amplified by PCR using primers $1 \mathrm{~F}$ and $1 \mathrm{R}$ (Supplementary Table 2) and inserted into the HMT vector at the SspI site by Gibson assembly to form HMT-IseG(-23aa). A surface-entropy reduction mutation, changing a.a. 133-136 from EDAR to AAAA, was introduced by QuickChange site-directed mutagenesis using primers $2 \mathrm{~F}$ and $2 \mathrm{R}$ (Supplementary Table 2) to form pET28-HMT-IseG(-23aa 133EDAR136-AAAA). The DpIseK fragment was inserted into the HMT vector at the SspI site for the expression of recombinant MBP-IseK fusion protein and subsequent ITC experiment. The BwTauF fragment was inserted into the HT vector at the SspI site.

Recombinant protein production and purification. IseG and MBP-IseH were heterologously expressed in Escherichia coli BL21 (DE3) cells harboring the plasmids pET-28a(+)-His 6 -IseG and HMT-IseH, respectively. For IseH, the cells were co-transformed with the plasmid pTf16 (TaKaRa) for co-expression of the tig chaperone. For IseG expression, LB containing $50 \mu \mathrm{g} / \mathrm{mL}$ kanamycin was used, while for MBP-IseH, LB containing $50 \mu \mathrm{g} / \mathrm{mL}$ kanamycin and $25 \mu \mathrm{g} / \mathrm{mL}$ chloramphenicol was used. Single colonies were inoculated into $5 \mathrm{~mL}$ starter cultures, grown at $37^{\circ} \mathrm{C}$ overnight, and transferred into $1 \mathrm{~L}$ of medium. For MPB-IseH, $0.5 \mathrm{mg} / \mathrm{mL} \mathrm{L}$-arabinose was added to induce expression of the chaperone. The cultures were grown at $37^{\circ} \mathrm{C}$ with shaking at $220 \mathrm{rpm}$. When $\mathrm{OD}_{600}$ reached $\sim 0.8$, the temperature was decreased to $16^{\circ} \mathrm{C}$ and isopropyl $\beta$-D-1-thiogalactopyranoside (IPTG) was added to a final concentration of $0.3 \mathrm{mM}$. Cells were harvested by centrifugation $\left(4000 \times \mathrm{g}\right.$ for $10 \mathrm{~min}$ at $\left.4{ }^{\circ} \mathrm{C}\right)$ after $16 \mathrm{~h}^{14}$. Cells $(\sim 1 \mathrm{~g}$ wet weight were suspended in $5 \mathrm{~mL}$ of lysis buffer [ $50 \mathrm{mM}$ Tris/ $\mathrm{HCl}, \mathrm{pH} 8.0,1 \mathrm{mM}$ phenylmethanesulfonyl fluoride (PMSF), $0.2 \mathrm{mg} / \mathrm{mL}$ lysozyme, $0.03 \%$ Triton X-100, and $1 \mu \mathrm{L}$ of DNase I (Roche)]. The cell suspension was frozen in a $-80^{\circ} \mathrm{C}$ freezer, and then thawed and incubated at room temperature (RT) for $50 \mathrm{~min}$ to allow lysis. $15 \mathrm{~mL}$ of buffer A [ $20 \mathrm{mM}$ Tris/ $\mathrm{HCl}, \mathrm{pH} 7.5$, and $5 \mathrm{mM} \beta$-mercaptoethanol (BME)] containing $1.3 \%$ streptomycin sulfate was added, and the precipitated DNA was removed by centrifugation $\left(20,000 \times g\right.$ for $5 \mathrm{~min}$ at $\left.4{ }^{\circ} \mathrm{C}\right)$. Solid $\left(\mathrm{NH}_{4}\right)_{2} \mathrm{SO}_{4}$ was then added to $70 \%$ saturation. The solution was shaken for an additional $10 \mathrm{~min}$, and the precipitated protein was isolated by centrifugation $(20,000 \times g$ for $10 \mathrm{~min}$ at $4{ }^{\circ} \mathrm{C}$ ). The pellet was dissolved in $10 \mathrm{~mL}$ of buffer B (buffer A containing $0.2 \mathrm{M}$ $\mathrm{KCl}$ ), filtered and applied to a $2 \mathrm{~mL}$ TALON (Clontech) gravity column, preequilibrated with buffer B. The column was washed with 10 column volumes (CV) of buffer B, and protein was eluted with $5 \mathrm{CV}$ of buffer B containing $150 \mathrm{mM}$ imidazole. The eluted protein was precipitated with solid $\left(\mathrm{NH}_{4}\right)_{2} \mathrm{SO}_{4}$ to $70 \%$ saturation and isolated by centrifugation $\left(20,000 \times \mathrm{g}\right.$ for $10 \mathrm{~min}$ at $\left.4{ }^{\circ} \mathrm{C}\right)$. The pellet was dissolved in $0.5 \mathrm{~mL}$ of buffer B and desalted using a G25 column (GE, thermostat jacket tube XK16/20, packed $15 \mathrm{~cm} \times 2 \mathrm{~cm}^{2}, 30 \mathrm{~mL}$ ), pre-equilibrated with buffer C [ $20 \mathrm{mM}$ Tris/ $\mathrm{HCl}, \mathrm{pH} 7.5,100 \mathrm{mM} \mathrm{KCl}, 10 \%$ glycerol, and $1 \mathrm{mM}$ tris (2-carboxyethyl)phosphine (TCEP) for IseG or $1 \mathrm{mM}$ dithiothreitol (DTT) for MBP-IseH] ${ }^{14}$. The eluted protein was concentrated to $\sim 400 \mu \mathrm{L}$ by ultrafiltration (Sartorius VIVASPIN TURBO 15 (30,000MWCO), frozen in aliquots in liquid $\mathrm{N}_{2}$, and stored at $-80^{\circ} \mathrm{C}$. The purified IseG $\left(\varepsilon_{280}=129,150 \mathrm{M}^{-1} \mathrm{~cm}^{-1}\right)$ and MBP-IseH $\left(\varepsilon_{280}=93,740 \mathrm{M}^{-1} \mathrm{~cm}^{-1}\right)$ were examined by SDS-PAGE on a $12 \%$ gel.

Details for recombinant production and purification of the other proteins, including IseG ( -23 a.a.), ScADH, $B w$ IseK, and $B w$ TauF, are provided in the Supplementary Methods. MBP-IseH was used for biochemical experiments 
without cleavage of the MBP tag. The MBP tag of MBP-DpIseK was cleaved and removed prior to ITC experiments.

Analysis of the oligomeric state of IseG. A $2.5 \mathrm{mg} / \mathrm{mL}$ solution of IseG $(-23$ a.a.) was analysed by gel filtration. A $2 \mathrm{~mL}$ protein solution was injected into a Superdex 200 gel filtration column $(300 \mathrm{~mL})$ and eluted over $170 \mathrm{~min}$ with buffer D (10 mM HEPES/KOH, pH 7.4, $250 \mathrm{mM} \mathrm{KCl,} 10 \mathrm{mM} \mathrm{BME})$ at $3 \mathrm{~mL} / \mathrm{min}$. The same conditions were used to analyze a mixture of molecular weight markers. The molecular weights of the proteins were calculated from their elution volumes, using a second-degree polynomial for the relationship between $\log$ (molecular weight) and retention time. The observed molecular weight for IseG ( -23 a.a.) was 196 $\mathrm{kDa}$, whereas the calculated molecular weight for IseG monomer is $91.3 \mathrm{kDa}$. This result indicates that IseG exists as a dimer in solution, which is consistent with the oligomeric state of pyruvate formate-lyase and other GREs studied to date ${ }^{43}$.

[Fe-S] cluster reconstitution for MBP-IseH. A solution of MBP-IseH (50 $\mu \mathrm{M})$ was degassed on a Schlenk line and brought into the glovebox. The reconstitution buffer contained $10 \mathrm{mM}$ DTT and $100 \mathrm{mM}$ Tris- $\mathrm{HCl}, \mathrm{pH}$ 7.5. A solution of ferrous ammonium sulfate (12 eq.) was added followed by a solution of sodium sulfide (12 eq.). The mixture was incubated overnight at $4{ }^{\circ} \mathrm{C}$ in a cooling-heating block (Dry Bath H2O3-100C, Coyote Bioscience, Beijing, China). A solution of EDTA (12 eq.) was then added, and excess of iron and sulfide removed by repeated concentration with a centrifugal filter unit (1.5 mL YM-30 Amicon, Millipore), and dilution with buffer containing $20 \mathrm{mM}$ Tris- $\mathrm{HCl}, \mathrm{pH} 7.5$ and $0.1 \mathrm{M} \mathrm{KCl}$.

Ferrozine (3-(2-pyridyl)-5,6-diphenyl-1,2,4-triazine-p, $\mathrm{p}^{\prime}$-disulfonic acid monosodium salt) assays were carried out to quantitate iron contents in as-isolated and reconstituted MPB-IseH proteins. The standard curve was established with "Iron standard for AAS" (Fluka catalog \# 16596) in a range from 0-600 $\mu$ M. Briefly, $50 \mu \mathrm{L}$ protein sample was mixed with $100 \mu \mathrm{L} 2 \mathrm{M} \mathrm{HCl}$. The protein was denatured in a boiling water bath for $10 \mathrm{~min}$. The solution was then centrifuged for $5 \mathrm{~min}$ to remove precipitated protein. After cooling to RT, $150 \mu \mathrm{L}$ saturated ammonium acetate, $150 \mu \mathrm{L}$ freshly prepared $10 \mathrm{mM}$ sodium ascorbate, and $200 \mu \mathrm{L} 10 \mathrm{mM}$ ferrozine were added and mixed. $200 \mu \mathrm{L}$ of the mixture was transferred to a 96 -well plate for the measurement of $A_{562}$ with a Tecan M200 plate reader and the reading was referred to the standard curve for iron quantitation. The sulfide contents of asisolated and reconstituted MBP-IseH were determined by measuring the absorbance of methylene blue formed upon reaction with $N, N$-dimethyl-pphenylenediamine dihydrochloride (DPD) ${ }^{44,45}$. The purity of MBP-IseH was estimated to be $50 \%$ based on densitometry analysis of the Coomassie-stained SDSPAGE gel using the software ImageJ and used to estimate the Fe and S contents per IseH monomer.

UV-Vis absorption spectra of the reconstituted MBP-IseH. A solution of reconstituted MBP-IseH was diluted to $10 \mu \mathrm{M}$ with a buffer containing $20 \mathrm{mM}$ Tris/ $\mathrm{HCl}, \mathrm{pH} 7.5,100 \mathrm{mM} \mathrm{KCl}$. Samples were transferred into a septum-sealed anaerobic cuvette (Starna Cells, Quartz Septum Cell), taken out of the glovebox and the absorption spectrum acquired in the $200-800 \mathrm{~nm}$ range using a Hitachi U3900 spectrometer. To obtain the absorption spectrum of reduced IseH, 10 equivalents of $\mathrm{Ti}(\mathrm{III})$ citrate or 100 equivalents of sodium dithionite $(\mathrm{NaDT})$ was injected using a Hamilton air-tight syringe and incubated for 5 or $15 \mathrm{~min}$ respectively prior to the absorbance measurement. The UV-Vis absorption spectra exhibited features characteristic of $[4 \mathrm{Fe}-4 \mathrm{~S}]^{2+}$ clusters, which disappeared upon reduction. Correcting for the $50 \%$ purity of $\mathrm{MBP}$-IseH, the extinction coefficient of the reconstituted MBP-IseH [4Fe-4S] clusters was estimated to be $38 \mathrm{mM}^{-1} \mathrm{~cm}^{-1}$. Given the approximate $\varepsilon_{410 \mathrm{~nm}}$ of $15 \mathrm{mM}^{-1} \mathrm{~cm}^{-1}$ per cluster ${ }^{46}$, we estimated that $\sim 2.5$ [4Fe-4S] clusters per monomer were reconstituted, consistent with the measured $\mathrm{Fe}$ and $\mathrm{S}$ contents.

LC-MS assays for SAM cleavage by IseH. Detection of IseH catalyzed SAM cleavage and product formation using LC-MS assays were performed as described elsewhere ${ }^{47}$. A reaction mixture (500 $\mu \mathrm{L}$ total volume) containing $20 \mathrm{mM} \mathrm{Tris} / \mathrm{HCl}$, $\mathrm{pH} 7.5,100 \mathrm{mM} \mathrm{KCl}, 200 \mu \mathrm{M} \mathrm{Ti}(\mathrm{III})$ citrate, and $20 \mu \mathrm{M}$ reconstituted MBP-IseH was incubated for $15 \mathrm{~min}$ at RT in the glovebox to allow the reduction of IseH. SAM (Sigma, $0.5 \mathrm{mM}$ final concentration) was added to initiate the cleavage reaction. A control assay omitting Ti (III) was also performed. The reaction was incubated at RT in the glovebox overnight and quenched with formic acid $(5 \% \mathrm{v} / \mathrm{v}$ final concentration). The reaction mixture was then incubated in a boiling waterbath for $45 \mathrm{~s}$ to completely denature the protein. The precipitated protein was removed by centrifugation at $14,000 \times g$ for $10 \mathrm{~min}$. and the supernatant was filtered through a $0.22-\mu \mathrm{m}$ PES membrane. A $20 \mu \mathrm{L}$ portion of the supernatant was analyzed by an Agilent 6420 Triple Quadrupole LC/MS instrument (Agilent Technologies) on a C18 column (Advantage ECHELON C18 $4 \mu \mathrm{m} 150 \times 2.1 \mathrm{~mm}$ P/N: ADV8010, manufactured by ANALYTICAL). The solvent system consisted of water $(\mathrm{A})$ and acetonitrile (B), and the sample was eluted with a linear gradient of $0-16 \%$ B over $30 \mathrm{~min}$, with a flow rate of $0.5 \mathrm{~mL} / \mathrm{min}$. The products were detected by UV absorption at $257 \mathrm{~nm}$, and $5^{\prime}$-dA was compared to commercial standard and verified by mass spectrometry.
EPR detection of IseG glycyl radical formation. Continuous wave X-band electron paramagnetic resonance (EPR) spectroscopy was used to characterize the IseG glycyl radical. A $240 \mu \mathrm{L}$ reaction mixture containing $20 \mathrm{mM}$ HEPES, $\mathrm{pH} 7.5$ $0.1 \mathrm{M} \mathrm{KCl}, 20 \mu \mathrm{M}$ IseG, $80 \mu \mathrm{M}$ reconstituted MBP-IseH, $1 \mathrm{mM} \mathrm{SAM}, 100 \mu \mathrm{M}$ Ti (III) citrate and 5\% glycerol was incubated at RT for $10 \mathrm{~min}$ in the glovebox. A control sample omitting Ti(III) citrate was also prepared. All samples were loaded into EPR tubes with $4 \mathrm{~mm}$ o.d. and 8" length (Wilmad Lab-Glass, 734-LPV-7), sealed with a rubber stopper, removed from the glovebox and frozen in liquid nitrogen prior to EPR analysis. The perpendicular mode X-band EPR spectra were recorded using a Bruker E500 EPR spectrometer. Data acquisition was performed with Xepr software (Bruker). The EPR spectra represent an average of 30 scans and were recorded under the following conditions: temperature, $90 \mathrm{~K}$; center field, 3370 Gauss; range, 200 Gauss; microwave power, $10 \mu \mathrm{W}$; microwave frequency, 9.44 $\mathrm{MHz}$; modulation amplitude, $0.5 \mathrm{mT}$; modulation frequency, $100 \mathrm{kHz}$; time constant, $20.48 \mathrm{~ms}$; conversion time, $30 \mathrm{~ms}$; scan time, $92.16 \mathrm{~s}$; and receiver gain, $43 \mathrm{~dB}$. The experimental spectra for the glycyl radical were modeled with Bruker Xepr spin fit to obtain g values, hyperfine coupling constants, and line widths. Double integration of the simulated spectra was used to measure spin concentration.

Fuchsin assay for sulfite detection. Sulfite was detected using a colorimetric assay involving the formation of a colored complex between sulfite and fuchsin dye in acidic solution ${ }^{48}$. IseG activation was carried out as described for the EPR experiments except that glycerol was omitted. A $100 \mu \mathrm{L}$ reaction mixture containing $10 \mu \mathrm{M}$ activated IseG, $10 \mu \mathrm{M}$ ScADH1, $1 \mathrm{mM} \mathrm{NADH}, 600 \mu \mathrm{M}$ isethionate (Adamas) was incubated at $30{ }^{\circ} \mathrm{C}$ for $1 \mathrm{~h}$ in the glovebox. A negative control omitting isethionate was also performed. While the reaction incubated, stock solution A $\left(0.8 \mathrm{M} \mathrm{H}_{2} \mathrm{SO}_{4}, 0.08 \%\right.$ Fuchsin and $1.6 \%$ formaldehyde, mixed $\left.7: 2: 1\right)$ was freshly prepared. A $50 \mu \mathrm{L}$ portion per reaction sample was mixed with $950 \mu \mathrm{L}$ of solution A, incubated for $10 \mathrm{~min}$, and the UV-Vis absorption spectra were collected.

LC-MS assay for acetaldehyde detection. A $100 \mu \mathrm{L}$ reaction mixture containing $10 \mu \mathrm{M}$ IseG, $40 \mu \mathrm{M}$ IseH, $0.05 \mathrm{mM}$ Ti(III) citrate, $0.5 \mathrm{mM} \mathrm{SAM}$, and $10 \mathrm{mM}$ isethionate was incubated at $30^{\circ} \mathrm{C}$ for $20 \mathrm{~min}$ in the glovebox. Two negative controls omitting either SAM or isethionate were also performed. The acetaldehyde product was detected by derivatization with 2,4-dinitrophenylhydrazine (DNPH) $(J \& K)^{49}$. After the enzyme reaction, $100 \mu \mathrm{L}$ of reaction solution was mixed with $1.1 \mathrm{~mL}$ of $0.73 \mathrm{M}$ sodium acetate buffer $\mathrm{pH} 5.0$, followed by $800 \mu \mathrm{L}$ of freshly prepared DNPH solution ( $40 \mathrm{mg}$ dissolved in $100 \mathrm{~mL}$ methanol), and the mixture was incubated at $50{ }^{\circ} \mathrm{C}$ for $1 \mathrm{~h}$ and then filtered prior to LC-MS analysis. A commercial acetaldehyde-DNPH standard (Sigma) $(40 \mathrm{mg}$ in $250 \mathrm{~mL} 40 \%$ methanol and $60 \%$ $\mathrm{H}_{2} \mathrm{O}$ ) was also prepared.

LC-MS analysis was performed on an Agilent 6420 Triple Quadrupole LC/MS instrument (Agilent Technologies). The drying gas temperature was maintained at $350^{\circ} \mathrm{C}$ with a flow rate of $12 \mathrm{~L} \mathrm{~min}^{-1}$ and a nebulizer pressure of $25 \mathrm{psi}$. LC-MS analysis was carried out with $20 \mu \mathrm{L}$ sample volume on an Agilent ZORBAX SBC18 column $(4.6 \times 250 \mathrm{~mm}$, product number $880975-902)$. The column was equilibrated with $50 \% \mathrm{H}_{2} \mathrm{O} / 50 \% \mathrm{CH}_{3} \mathrm{CN}$ and developed at a flow rate of $1.0 \mathrm{~mL} /$ min. UV detection was set at $360 \mathrm{~nm}$. The LC elution profile for the complete assay contained two major peaks with retention times of 5.1 and 12.9 min corresponding to DNPH and acetaldehyde-DNPH, respectively, as identified by ESI-MS $(\mathrm{m} / \mathrm{z})$ and by comparison to the respective standards. The acetaldehyde-DNPH peak was absent in both negative controls. Taken together, these observations demonstrate that IseG catalyzes the cleavage of isethionate to form acetaldehyde.

Spectrophotometric coupled assay for acetaldehyde formation. Assays involving complete substrate turnover were conducted to determine the stoichiometry of substrate consumed to products formed. An NADH-coupled spectrophotometric assay was used to quantitate acetaldehyde formation. A $100 \mu \mathrm{L}$ reaction mixture containing $10 \mu \mathrm{M}$ activated IseG, $10 \mu \mathrm{M}$ ScADH1, $0.3 \mathrm{mM}$ NADH and 100,150 , or $200 \mu \mathrm{M}$ isethionate was incubated at RT for $40 \mathrm{~min}$ in the glovebox. Control assays omitting either isethionate, SAM, IseH or IseG were also performed. Assays in which isethionate was substituted with $200 \mu \mathrm{M}$ taurine (Solarbio) or ethanolamine (Adamas) were also performed to examine the substrate specificity of IseG. The decrease of $A_{340 \mathrm{~nm}}$ for samples contained in a $1-\mathrm{cm}$ cuvette was monitored using a Thermo Scientific Nanodrop OneC machine (cuvette mode) in the glovebox and used to calculate the substrate turnover.

DTNB assay to quantitate sulfite formation. DTNB (5,5-dithio-bis-(2-nitrobenzoic acid), Ellman's Reagent) was used to quantitate sulfite formation in the complete turn over assays ${ }^{50}$. ScADH1 and $\mathrm{NADH}$ were omitted in these assays. Since the proteins, residual DTT and metals can interfere with the DTNB assays, higher isethionate concentrations were used. A $40 \mu \mathrm{L}$ reaction mixture containing $10 \mu \mathrm{M}$ activated IseG and $1,1.5$, and $2 \mathrm{mM}$ isethionate was incubated at RT for $1 \mathrm{~h}$ in the glovebox. $40 \mu \mathrm{L}$ of $3 \mathrm{mM}$ EDTA and $120 \mu \mathrm{L}$ of $0.1 \mathrm{M}$ phosphate buffer $\mathrm{pH}$ 8.0 were then added and mixed. $70 \mu \mathrm{L}$ of the mixture was then added to $30 \mu \mathrm{L}$ freshly prepared DTNB solution ( $5 \mathrm{mM}$ in $0.1 \mathrm{M}$ phosphate buffer, $\mathrm{pH} 8.0$ ) and subjected to $A_{412 \mathrm{~nm}}$ measurement. Sulfite formation was calculated by referring to 
a standard curve established with known concentrations of sulfite spiked into the same reaction mixture omitting isethionate.

Kinetic assays. The spectrophotometric coupled kinetic assays (assay volume $100 \mu \mathrm{L}$ ) for IseG activity were conducted at RT in a $1 \mathrm{~cm}$ Eppendorf cuvette using the cuvette mode of the Thermo Scientific Nanodrop OneC in the glovebox. The absorbance of each assay mixture was monitored at $340 \mathrm{~nm}$, at $2 \mathrm{~s}$ intervals. For enzyme dose-dependent assays, the enzyme concentration was varied while a fixed, saturating substrate concentration of $400 \mathrm{mM}$ isethionate was used. To obtain the Michaelis-Menten kinetic parameters, assays were performed with varied substrate concentrations and a fixed enzyme concentration of $250 \mathrm{nM}$ IseG. GraphPad Prism6 was used for data analysis.

X-ray crystal structure of IseG. Initial screening of IseG crystals was performed using an automated liquid handling robotic system (Gryphon, Art Robbins) in 96well format by the sitting-drop vapor diffusion method. The screens were set up at $295 \mathrm{~K}$ using various sparse matrix crystal screening kits from Hampton Research and Molecular Dimensions. Several crystallization conditions gave thin plate-shape crystals. After further optimization using the hanging-drop vapor-diffusion method in 24-well plates with protein concentration at $10 \mathrm{mg} / \mathrm{mL}$, we obtained crystals large enough for single crystal X-ray diffraction studies. The best condition yielding large plate crystals was $0.2 \mathrm{M}$ sodium malonate dibasic monohydrate, 0.1 M Bis-Tris propane, $\mathrm{pH} \mathrm{8.5,20 \%} \mathrm{(w/v)} \mathrm{PEG3350} \mathrm{plus} 500 \mathrm{mM}$ isethionate.

Crystals were flash-cooled in liquid nitrogen using reservoir solution containing $30 \%$ glycerol as cryoprotectant. Diffraction data was collected on a local Rigaku Xray diffractor (XtaLAB P200 MM007HF) to a resolution of $2.40 \AA$. The data set was indexed, integrated and scaled using HKL3000 suite ${ }^{51}$. Molecular replacement was performed by PHENIX ${ }^{52}$ using a homology model of IseG created by

Phyre 2 server $^{53}$. The structure was manually built according to the modified experimental electron density using $\operatorname{Coot}^{54}$ and further refined by PHENIX ${ }^{52}$ in iterative cycles. Supplementary Table 3 contains the statistics for data collection and final refinement. All structural figures were generated with UCSF Chimera ${ }^{55}$.

Growth of SSRB with different terminal electron acceptors. Desulfovibrio piger (DSM 749) was purchased from DSMZ, and cultured to investigate whether it can utilize taurine or isethionate as TEA. Cells were first inoculated into DSM641 defined medium and cultivated anaerobically at $37^{\circ} \mathrm{C}$ for 2 days. Then $100 \mu \mathrm{L}$ portions of the starter culture were transferred into three anaerobic bottles containing $5 \mathrm{~mL}$ modified DSM 641 defined medium, omitting $\mathrm{Na}_{2} \mathrm{SO}_{4}$ and with $\mathrm{MgSO}_{4}$ replaced by $\mathrm{MgCl}_{2}$. Different TEAs (20 mM) were added: (1) $\mathrm{Na}_{2} \mathrm{SO}_{4}$, (2) taurine, and (3) sodium isethionate. After $27 \mathrm{~h}$ incubation at $37^{\circ} \mathrm{C}$, the cultures containing $\mathrm{Na}_{2} \mathrm{SO}_{4}$ and isethionate, but not the one containing taurine, became turbid and black, indicating bacterial growth and formation of iron sulfide precipitates as a result of sulfate/sulfite reduction.

Bilophila wadsworthia (DSM 11045) was purchased from DSMZ. Cells were first inoculated into $\mathrm{ABB}$ medium supplemented with $5 \mathrm{mM}$ taurine and cultivated anaerobically at $30^{\circ} \mathrm{C}$ for $3-7$ days. Then $100 \mu \mathrm{L}$ portions of the starter culture were transferred into three anaerobic bottles containing $5 \mathrm{~mL}$ modified DSM 503 medium, omitting taurine and supplemented with $60 \mathrm{mM} \mathrm{Na}$-formate and $200 \mu \mathrm{g} /$ L 1,4-naphthochinone. Different TEAs $\left(20 \mathrm{mM}\right.$ ) were added: (1) $\mathrm{Na}_{2} \mathrm{~S}_{2} \mathrm{O}_{3}$ (with 20 $\mathrm{mM}$ sodium pyruvate added as a carbon and electron source), (2) taurine, and (3) isethionate. After $3-7$ days incubation at $30^{\circ} \mathrm{C}$, all three cultures became turbid and contain black precipitate, indicating bacterial growth and FeS formation.

Detection of $\mathbf{H}_{\mathbf{2}} \mathbf{S}$ formation in SSRB cell culture. D. piger was inoculated into 20 $\mathrm{mL}$ anaerobic starter culture containing DSMZ_Medium 641. $20 \mu \mathrm{L}$ starter culture was transferred into two anaerobic vials containing $5 \mathrm{~mL}$ modified DSM 641 medium omitting $\mathrm{SO}_{4}{ }^{2-}$ and $\mathrm{S}^{2-}$ salt. $20 \mathrm{mM}$ isethionate was added to one of the two vials. After 3 days' incubation at $37^{\circ} \mathrm{C}$, the culture supplemented with isethionate exhibited turbidity with bacterial growth and black precipitate, while the culture without isethionate remained clear. From both vials, $1 \mathrm{~mL}$ headgas was taken out using a syringe, and introduced slowly into the liquid in an Eppendorf tube, containing $800 \mu \mathrm{L}$ of $0.75 \%$ zinc acetate and $50 \mu \mathrm{L}$ of $7 \% \mathrm{NaOH}$. The mixture was incubated at room temperature for $15 \mathrm{~min} .150 \mu \mathrm{L}$ of $0.1 \%$ DPD ( $1 \mathrm{mg}$ DPD dissolved in $1 \mathrm{~mL} 5 \mathrm{~N} \mathrm{HCl}$ ) and $150 \mu \mathrm{L}$ of $10 \mathrm{mM} \mathrm{FeCl}_{3}$ (dissolved in $1 \mathrm{~N} \mathrm{HCl}$ ) were added to the reaction mixture. The reaction mixture was incubated at $30^{\circ} \mathrm{C}$ for $20 \mathrm{~min}$ and centrifuged at $14,000 \times \mathrm{g}$ for $5 \mathrm{~min}$. The supernatant was subjected to absorbance measurement at $670 \mathrm{~nm}$ using a Tecan M200 plate reader.

Protein identification by SDS-PAGE and mass spectrometry. Cells were harvested by centrifugation, lysed by boiling in Laemmli loading buffer, and analysed on a $10 \%$ SDS-PAGE gel. Prominent protein bands induced by growth on sulfonate substrates were manually excised and sent to Beijing Proteomic Research Centre for analysis. After in-gel digestion and extraction, the peptide mixtures were loaded onto LCESI-Q-TOF MS. The peptide hits searched against the Desulfovibrio piger protein database GCF_900116045.1 and GCF_000156375.1 (ATCC 29098), or the Bilophila wadsworthia protein database GCF_000185705.2 (Bilo_wads_3_1_6_V2) and GCF_000701705.1 (ATCC 49260), by MASCOT, Protein identifications were performed based on probability-based Mowse scoring algorithm with a confidence level of $95 \%$.

For D. piger, isethionate-grown cells, but not sulfate-grown cells, exhibited a prominent protein band migrating at $95 \mathrm{kDa}$. This band was identified as glycyl radical protein from Desulfovibrio piger WP_006008826.1 and WP_072335172.1, corresponding to IseG (Supplementary Data 2). For B. wadsworthia, taurine- and isethionate-grown cells, but not the $\mathrm{Na}_{2} \mathrm{~S}_{2} \mathrm{O}_{3}$ grown cells, exhibited a protein band at $95 \mathrm{kDa}$. Cells grown on taurine also exhibited a prominent protein band with molecular weight of $\sim 40 \mathrm{kD}$. The $95 \mathrm{kDa}$ band was identified as glycyl radical protein from Bilophila wadsworthia WP 005024906.1, corresponding to IseG (Supplementary Data 3 and 4). The $40 \mathrm{kDa}$ band was identified as $\mathrm{AlaDH}$ and TauF (top two hits in Supplementary Data 5).

ITC assays for DplseK. ITC measurements were performed on a PEAQ-ITC instrument (Malvern). The buffer for all of the experiments was $20 \mathrm{mM}$ HEPES, pH 8.0 with $10 \mathrm{mM} \mathrm{NaCl}$. Titrations consisted of 13 injections of $2 \mu \mathrm{L}$ of $130 \mu \mathrm{M}$ isethionate or taurine into the cell containing $50 \mu \mathrm{M} D$ p IseK or control buffer. The reference cell contained deionized water. Experiments were performed at $25^{\circ} \mathrm{C}$ and a stirring speed of $750 \mathrm{rpm}$. Background titrations measuring the nonspecific heat released by the dilution of the ligands in the absence of protein were obtained and subtracted from the raw titration. The datasets were analysed using a single-site binding model using the MicroCal PEAQ-ITC software. Fitting was performed to derive stoichiometry, binding affinity, and changes in enthalpy $(\Delta \mathrm{H})$ and entropy $(\Delta \mathrm{S})$. A $K_{\mathrm{d}}$ of $0.5 \mu \mathrm{M}$ was measured for isethionate. The $N$ value is estimated to be 0.25 , indicating sub-stoichiometric binding possibly due to a fraction of pre-bound or inactive protein. No interaction was observed for taurine.

Enzyme activity assay for BwTauF. Sulfoacetaldehyde is unstable and required to be introduced as a bisulfite adduct ${ }^{56}$. A $200 \mu \mathrm{L}$ mixture containing $0.1 \mathrm{M}$ Tris, $\mathrm{pH} 7.5,0.1 \mathrm{M} \mathrm{KCl}, 5 \mathrm{mM}$ sulfoacetaldehyde, $0.5 \mathrm{mM} \mathrm{NADH}$ was pre-mixed in a 96-well plate, followed by addition of $0.5 \mu \mathrm{g} B w \mathrm{TauF}$ to initiate the reaction. Absorbance at $340 \mathrm{~nm}$ was monitored for $1.5 \mathrm{~min}$ at $15 \mathrm{~s}$ intervals. Negative controls omitting either sulfoacetaldehyde or $B w$ TauF were included. The timedependent decrease of $A_{340}$ in the complete assay but not in any of the negative controls demonstrates that $B w \mathrm{TauF}$ is a sulfoacetaldehyde reductase.

Reporting summary. Further information on experimental design is available in the Nature Research Reporting Summary linked to this article.

\section{Data availability}

Coordinates and structure factors of IseG in complex with isethionate have been deposited in the Protein Data Bank with accession code 5YMR. Source data underlying Fig. 2a-c, Supplementary Fig. 3-10, 13-15 are provided as a Source Data file. Source data underlying Supplementary Fig. 2 and Figs. 4a, $4 \mathrm{~b}$ are provided as Supplementary Data 15. Other data are available from the corresponding authors upon reasonable request.

Received: 5 February 2019 Accepted: 21 March 2019

Published online: 08 April 2019

\section{References}

1. Cook, A. M. \& Denger, K. Dissimilation of the C2 sulfonates. Arch. Microbiol. 179, 1-6 (2002).

2. Lie, T. J., Pitta, T., Leadbetter, E. R., Godchaux, W. 3rd \& Leadbetter, J. R. Sulfonates: novel electron acceptors in anaerobic respiration. Arch. Microbiol. 166, 204-210 (1996).

3. Ripps, H. \& Shen, W. Review: taurine: a "very essential” amino acid. Mol. Vis 18, 2673-2686 (2012).

4. Ridlon, J. M., Wolf, P. G. \& Gaskins, H. R. Taurocholic acid metabolism by gut microbes and colon cancer. Gut Microbes 7, 201-215 (2016).

5. Fellman, J. H., Roth, E. S., Avedovech, N. A. \& McCarthy, K. D. The metabolism of taurine to isethionate. Arch. Biochem. Biophys. 204, 560-567 (1980).

6. Devkota, S. et al. Dietary-fat-induced taurocholic acid promotes pathobiont expansion and colitis in Il10-/- mice. Nature 487, 104-108 (2012).

7. Cook, A. M. \& Denger, K. Metabolism of taurine in microorganisms: a primer in molecular biodiversity? Adv. Exp. Med. Biol. 583, 3-13 (2006).

8. Eichhorn, E., van der Ploeg, J. R., Kertesz, M. A. \& Leisinger, T. Characterization of alpha-ketoglutarate-dependent taurine dioxygenase from Escherichia coli. J. Biol. Chem. 272, 23031-23036 (1997).

9. Eichhorn, E., van der Ploeg, J. R. \& Leisinger, T. Characterization of a twocomponent alkanesulfonate monooxygenase from Escherichia coli. J. Biol. Chem. 274, 26639-26646 (1999)

10. Ruff, J., Denger, K. \& Cook, A. M. Sulphoacetaldehyde acetyltransferase yields acetyl phosphate: purification from Alcaligenes defragrans and gene clusters in taurine degradation. Biochem. J. 369, 275-285 (2003). 
11. Kertesz, M. A. Riding the sulfur cycle-metabolism of sulfonates and sulfate esters in gram-negative bacteria. FEMS Microbiol. Rev. 24, 135-175 (2000).

12. Laue, H., Friedrich, M., Ruff, J. \& Cook, A. M. Dissimilatory sulfite reductase (desulfoviridin) of the taurine-degrading, non-sulfate-reducing bacterium Bilophila wadsworthia RZATAU contains a fused DsrB-DsrD subunit. J. Bacteriol. 183, 1727-1733 (2001).

13. Levin, B. J. et al. A prominent glycyl radical enzyme in human gut microbiomes metabolizes trans-4-hydroxy-l-proline. Science 355, eaai8386 (2017).

14. Liu, D. et al. Indoleacetate decarboxylase is a glycyl radical enzyme catalysing the formation of malodorant skatole. Nat. Commun. https://doi.org/10.1038/ s41467-018-06627-x (2018).

15. Zargar, $\mathrm{K}$. et al. In vitro characterization of phenylacetate decarboxylase, a novel enzyme catalyzing toluene biosynthesis in an anaerobic microbial community. Sci. Rep. 6, 31362 (2016).

16. Shisler, K. A. \& Broderick, J. B. Glycyl radical activating enzymes: structure, mechanism, and substrate interactions. Arch. Biochem. Biophys. 546, 64-71 (2014).

17. Atkinson, H. J., Morris, J. H., Ferrin, T. E. \& Babbitt, P. C. Using sequence similarity networks for visualization of relationships across diverse protein superfamilies. PLoS ONE 4, e4345 (2009).

18. Gerlt, J. A. et al. Enzyme Function Initiative-Enzyme Similarity Tool (EFIEST): a web tool for generating protein sequence similarity networks. Biochim. Biophys. Acta 1854, 1019-1037 (2015).

19. Shannon, P. et al. Cytoscape: a software environment for integrated models of biomolecular interaction networks. Genome Res. 13, 2498-2504 (2003).

20. Zarzycki, J., Erbilgin, O. \& Kerfeld, C. A. Bioinformatic characterization of glycyl radical enzyme-associated bacterial microcompartments. Appl. Environ. Microbiol. 81, 8315-8329 (2015).

21. Banerjee, R. \& Ragsdale, S. W. The many faces of vitamin B12: catalysis by cobalamin-dependent enzymes. Annu. Rev. Biochem. 72, 209-247 (2003).

22. Bodea, S., Funk, M. A., Balskus, E. P. \& Drennan, C. L. Molecular basis of C-N bond cleavage by the glycyl radical enzyme choline trimethylamine-lyase. Cell Chem. Biol. 23, 1206-1216 (2016).

23. Mulligan, C., Fischer, M. \& Thomas, G. H. Tripartite ATP-independent periplasmic (TRAP) transporters in bacteria and archaea. FEMS Microbiol. Rev. 35, 68-86 (2011).

24. Vetting, M. W. et al. Experimental strategies for functional annotation and metabolism discovery: targeted screening of solute binding proteins and unbiased panning of metabolomes. Biochemistry 54, 909-931 (2015).

25. Selvaraj, B., Buckel, W., Golding, B. T., Ullmann, G. M. \& Martins, B. M. Structure and function of 4-hydroxyphenylacetate decarboxylase and its cognate activating enzyme. J. Mol. Microbiol. Biotechnol. 26, 76-91 (2016).

26. Krebs, C., Henshaw, T. F., Cheek, J., Huynh, B. H. \& Broderick, J. B. Conversion of $3 \mathrm{Fe}-4 \mathrm{~S}$ to $4 \mathrm{Fe}-4 \mathrm{~S}$ clusters in native pyruvate formate-lyase activating enzyme: mössbauer characterization and implications for mechanism. J. Am. Chem. Soc. 122, 12497-12506 (2000).

27. Kovacevic, B. et al. Computational tale of two enzymes: glycerol dehydration with or without B12. J. Am. Chem. Soc. 140, 8487-8496 (2018).

28. Backman, L. R. F., Funk, M. A., Dawson, C. D. \& Drennan, C. L. New tricks for the glycyl radical enzyme family. Crit. Rev. Biochem. Mol. Biol. 52, 674-695 (2017).

29. Lie, T. J., Godchaux, W. \& Leadbetter, E. R. Sulfonates as terminal electron acceptors for growth of sulfite-reducing bacteria (Desulfitobacterium spp.) and sulfate-reducing bacteria: effects of inhibitors of sulfidogenesis. Appl. Environ. Microbiol. 65, 4611-4617 (1999).

30. Laue, H., Denger, K. \& Cook, A. M. Taurine reduction in anaerobic respiration of Bilophila wadsworthia RZATAU. Appl. Environ. Microbiol. 63, 2016-2021 (1997).

31. Weinitschke, S., Sharma, P. I., Stingl, U., Cook, A. M. \& Smits, T. H. Gene clusters involved in isethionate degradation by terrestrial and marine bacteria. Appl. Environ. Microbiol. 76, 618-621 (2010).

32. Rey, F. E. et al. Metabolic niche of a prominent sulfate-reducing human gut bacterium. Proc. Natl Acad. Sci. USA 110, 13582-13587 (2013).

33. Gorzynska, A. K., Denger, K., Cook, A. M. \& Smits, T. H. Inducible transcription of genes involved in taurine uptake and dissimilation by Silicibacter pomeroyi DSS-3T. Arch. Microbiol. 185, 402-406 (2006).

34. Laue, H. \& Cook, A. M. Biochemical and molecular characterization of taurine:pyruvate aminotransferase from the anaerobe Bilophila wadsworthia. Eur. J. Biochem. 267, 6841-6848 (2000).

35. Laue, H. \& Cook, A. M. Purification, properties and primary structure of alanine dehydrogenase involved in taurine metabolism in the anaerobe Bilophila wadsworthia. Arch. Microbiol. 174, 162-167 (2000).
36. Levin, B. J. \& Balskus, E. P. Characterization of 1,2-propanediol dehydratases reveals distinct mechanisms for B12-dependent and glycyl radical enzymes. Biochemistry 57, 3222-3226 (2018).

37. Yazici, C. et al. Race-dependent association of sulfidogenic bacteria with colorectal cancer. Gut 66, 1983-1994 (2017).

38. Finegold, S. M., Downes, J. \& Summanen, P. H. Microbiology of regressive autism. Anaerobe 18, 260-262 (2012).

39. Shen, X. et al. Microbial regulation of host hydrogen sulfide bioavailability and metabolism. Free Radic. Biol. Med. 60, 195-200 (2013).

40. Paul, B. D. \& Snyder, S. H. H2S: a novel gasotransmitter that signals by sulfhydration. Trends Biochem. Sci. 40, 687-700 (2015).

41. Ritz, N. L. et al. Sulfate-reducing bacteria impairs working memory in mice. Physiol. Behav. 157, 281-287 (2016).

42. Van Petegem, F., Clark, K. A., Chatelain, F. C. \& Minor, D. L. Jr. Structure of complex between a voltage-gated calcium channel beta-subunit and an alphasubunit domain. Nature 429, 671-675 (2004)

43. Vey, J. L. et al. Structural basis for glycyl radical formation by pyruvate formate-lyase activating enzyme. Proc. Natl Acad. Sci. USA 105, 16137-16141 (2008).

44. Siegel, L. M. A direct microdetermination for sulfide. Anal. Biochem. 11, 126-132 (1965).

45. Zhang, Y. et al. Dre2, a conserved eukaryotic Fe/S cluster protein, functions in cytosolic Fe/S protein biogenesis. Mol. Cell. Biol. 28, 5569-5582 (2008).

46. Shen, G. et al. SufR coordinates two $[4 \mathrm{Fe}-4 \mathrm{~S}] 2+, 1+$ clusters and functions as a transcriptional repressor of the sufBCDS operon and an autoregulator of sufR in cyanobacteria. J. Biol. Chem. 282, 31909-31919 (2007).

47. Yu, L., Blaser, M., Andrei, P. I., Pierik, A. J. \& Selmer, T. 4 Hydroxyphenylacetate decarboxylases: properties of a novel subclass of glycyl radical enzyme systems. Biochemistry 45, 9584-9592 (2006).

48. Denger, K., Ruff, J., Rein, U. \& Cook, A. M. Sulphoacetaldehyde sulpho-lyase (EC 4.4.1.12) from Desulfonispora thiosulfatigenes: purification, properties and primary sequence. Biochem. J. 357, 581-586 (2001).

49. Zhang, Q. et al. Radical-mediated enzymatic carbon chain fragmentationrecombination. Nat. Chem. Biol. 7, 154-160 (2011).

50. Man, M. \& Bryant, R. G. Reactions of thiosulfate and sulfite ions with DTNB: interference in sulfhydryl group analysis. Anal. Biochem. 57, 429-431 (1974).

51. Minor, W., Cymborowski, M., Otwinowski, Z. \& Chruszcz, M. HKL-3000: the integration of data reduction and structure solution-from diffraction images to an initial model in minutes. Acta Crystallogr. D Biol. Crystallogr. 62, 859-866 (2006).

52. Adams, P. D. et al. PHENIX: a comprehensive Python-based system for macromolecular structure solution. Acta Crystallogr. D Biol. Crystallogr. 66, 213-221 (2010)

53. Kelley, L. A., Mezulis, S., Yates, C. M., Wass, M. N. \& Sternberg, M. J. The Phyre2 web portal for protein modeling, prediction and analysis. Nat. Protoc. 10, 845-858 (2015).

54. Emsley, P. \& Cowtan, K. Coot: model-building tools for molecular graphics. Acta Crystallogr. D Biol. Crystallogr. 60, 2126-2132 (2004).

55. Pettersen, E. F. et al. UCSF Chimera-a visualization system for exploratory research and analysis. J. Comput. Chem. 25, 1605-1612 (2004).

56. Kondo, H., Anada, H., Osawa, K. \& Ishimoto, M. Formation of sulfoacetaldehyde from taurine in bacterial extracts. J. Biochem. 69, 621-623 (1971).

\section{Acknowledgements}

We thank the staff for assistance in using the in-house X-ray diffraction machine at Tianjin University and South China University of Technology, and X-ray facility on the beamline BL17U1 at Shanghai Synchrotron Radiation Facility (ref: Upgrade of macromolecular crystallography beamline BL17U1 at SSRF. Nuclear Science and Techniques 2018, 29(5):68.). We thank the instrument analytical center of School of Pharmaceutica Science and Technology at Tianjin University for providing the LC-MS analysis and Mr Zhi Li and Prof. Xiangyang Zhang for the helpful discussion. We thank Professor Suwen Zhao for the helpful discussion, and Professor Yunfei Du for the assistance in organic synthesis. This work was supported by National Natural Science Foundation of China (grant 31870049 and 31570060) (Y.Z.), National Key Research and Development Program of China (2017YFD0201400, 2017YFD0201403) (Z.Y.), and the Agency for Science, Research and Technology of Singapore Visiting Investigator Program (H.Z.).

\section{Author contributions}

M.X., Y.W., Y.Z., J.Z., L.L., Y.H., G.H., A.N.U., D.L., F.W., C.G., Y.T., M.L., Y.L., and Y.Z conducted the experiments; M.X., Y.W., E.L.A., H.Z., Z.Y., and Y.Z. designed the experiments and wrote the paper. 


\section{Additional information}

Supplementary Information accompanies this paper at https://doi.org/10.1038/s41467019-09618-8

Competing interests: The authors declare no competing interests.

Reprints and permission information is available online at http://npg.nature.com/ reprintsandpermissions/

Journal peer review information: Nature Communications thanks the anonymous reviewers for their contribution to the peer review of this work.

Publisher's note: Springer Nature remains neutral with regard to jurisdictional claims in published maps and institutional affiliations. (c) (i) Open Access This article is licensed under a Creative Commons Attribution 4.0 International License, which permits use, sharing, adaptation, distribution and reproduction in any medium or format, as long as you give appropriate credit to the original author(s) and the source, provide a link to the Creative Commons license, and indicate if changes were made. The images or other third party material in this article are included in the article's Creative Commons license, unless indicated otherwise in a credit line to the material. If material is not included in the article's Creative Commons license and your intended use is not permitted by statutory regulation or exceeds the permitted use, you will need to obtain permission directly from the copyright holder. To view a copy of this license, visit http://creativecommons.org/ licenses/by/4.0/.

(C) The Author(s) 2019 